The matching grant issued by the AATS remains active up to a total of $\$ 250,000$. Every individual one-time gift of $\$ \mathbf{5 , 0 0 0}$ or more will be doubled, making each dollar you contribute twice as valuable.

Learn more about the various ways to make a gift on aatsfoundation.org.

\section{Opportunities Available}

Visit aats.org to learn more about the following programs: Programs that are accepting applications from September 1 to December 1.

\section{ADULT CARDIAC}

Cardiac Surgical Robotics Fellowship

Sponsored by Intuitive Surgical

Chinese Surgeons International Training Program

Sponsored by Medtronic China

THORACIC

Thoracic Surgery Training Fellowship

Sponsored by Ethicon China

\section{MULTI-SPECIALTY}

Japanese Association for Thoracic Surgery Fellowship

Sponsored by Medtronic

\section{Summer Intern Scholarship}

Supported in part by Scanlan

Travel Awards to the AATS Annual Meeting

Programs that are accepting applications from mid-October to January 15. 2020.

\section{AATS Member for a Day Award}

Accompany an AATS Member Mentor during portions of the AATS 100th Annual Meeting through the AATS Member for a Day Award in New York, NY, from April 25-28, 2020. You will have the opportunity to gain insight into the cardiothoracic surgery specialty as well as network and build relationships within the cardiothoracic surgical community. You will also receive complimentary "all-access" registration to the scientific sessions at the Annual Meeting, including the AATS Member for a Day Saturday Evening Session and the AATS/TSRA Resident Luncheon.

Apply to be one of the 30 North American medical students, general surgery residents, up to third year integrated cardiothoracic surgery residents (I-6), and members of the American Physician Scientists Association (APSA) chosen to participate in the program.
AATS Cardiothoracic Surgery Resident Poster Competition

Senior cardiothoracic surgery residents and/or congenital heart surgery fellows from around the world have the opportunity to present a scientific poster of their clinical/investigative research at the 100th Annual Meeting in New York, NY, taking place from April 25-28, 2020. To represent your institution in the AATS Resident Poster Competition, provide a brief abstract (no more than 300 words) regarding the research. Posters may include research that has been previously presented and/or published.

\section{AATS Cardiothoracic Surgery Resident Case Report Competition}

Cardiothoracic surgery residents from around the world have the opportunity to present new original case studies at the 100th AATS Annual Meeting in New York, NY, April 25-28, 2020. To take part in the AATS Resident Case Report Competition, you need to provide a brief abstract (no more than 300 words) regarding an original case study, ie, an interesting/unusual case, identifying the issues you faced and the means you used to resolve it. You should be prepared to present in a mini oral presentation format at the Annual Meeting upon being selected. Case reports may not include research that has been previously presented and/or published.

\section{Perioperative/Team-Based Care Poster Competition}

Non-MD cardiothoracic surgical team professionals can participate in the AATS Perioperative/Team-Based Care Poster Competition at the AATS 100th Annual Meeting taking place in New York, NY, from April 25-28, 2020. The posters should reflect the participant's research findings and/or new and innovative ideas for successful approaches in the management of the cardiothoracic patient. Abstracts previously presented at a national or international meeting may be submitted. The purpose of the competition is to present research findings and share new and innovative ideas for successful approaches in the management of the cardiothoracic patient. To be eligible for the program, cardiothoracic perioperative/ team-based care professionals (NPs, PAs, Perfusionists, and RNs) must submit their abstract electronically through the submission site. 